\title{
An overview of pesticides in the development of agriculture crops
}

\author{
Arun Kumar Sharma* \\ Enviro Analytical Laboratories, Haridwar-249407 (Uttarakhand), India \\ Deepshikha Sharma \\ Enviro Analytical Laboratories, Haridwar-249407 (Uttarakhand), India \\ A.K. Chopra \\ Enviro Analytical Laboratories, Haridwar-249407 (Uttarakhand), India \\ *Corresponding author. Email: asharma.env@gmail.com
}

\begin{abstract}
The development of agriculture yield is closely related to the use of pesticides. This review categorizes and identifies the pathway of toxicity in the environment and their prevention measures to reduce risks from pesticide use. The inherent properties of selected pesticides released into the environment through different routes such as spray, drift, vaporization, surface run-off, unlawful acts, spills and drainage discharges, and through leaching or soil dust are related to their potential effects on environmental health. The intensive use of various pesticides like BHC, endrin, heptachlor, heptachlor epoxide, DDT, endosulfan and pyrethroids have harmful effects on non-target organisms and interfere in the development of agriculture crops. The preventive measures for pesticides are the crop rotation, use of protective equipment, integrated pest management, protection and regulation policy in pesticide application. The development of alternatives to pesticides is also needed in order to advance the design of better farming systems. A regular monitoring programme of pest management would help to improve the production of high quality of food as well as to protect the health of the environment and humans.
\end{abstract}

Keywords: Agriculture crops, Environment, Pesticides, Preventive measures, Toxicity

\section{Article Info}

https://doi.org/10.31018/

jans.vi.2254

Received: April 2, 2020

Revised: April 19, 2020

Accepted: May 9, 2020

\section{How to Cite}

Sharma A. K. et al. (2020) An overview of pesticides in the development of agriculture crops. Journal of Applied and Natural Science, 12 (2): $101-109$. https://doi.org/10.31018/ jans.vi.2254

\section{INTRODUCTION}

The widespread adoption of pesticides to control diseases is associated with increased crop yields, opening up of new agricultural land, and reduction in the incidence of vector-borne diseases. However, an increase in pest resistance has resulted in lower yields of crops and a revival of vector-borne diseases such as malaria. Besides, many health and environmental costs of intensive pesticide use have become harshly apparent (Eddleston et al., 2002 and Garrido et al., 2004). Pesticide pollution affects not only multiple other environmental factors such as soil, quality of air and water, crop productivity, micro and macro flora and fauna, etc. but also affects human health (Pimentel, 2005).

The consequences of such indiscriminate use of pesticides have recently become a matter of public concern in India (CSE, 2003). Every day humans come into contact with thousands of chemicals presented in a multitude of consumer products, and some of these products may contain pesticides. Exposure takes place through the occupational activities of the environment and by the ingestion of food and water. This exposure is of great concern to the government of the nations to estimate health risks to all the community and to the workers (Frenich et al., 2007). The pesticides significantly contribute to increased agronomic yield, protection of livestock, and removal of vector-transmitted disease. The contamination and ecological risk caused by the indiscriminate use of these chemicals and their large-scale production during the past few decades is of great concern (Aker et al. 2008 and Zhao and Hwang 2009).

An increase in the demand for agro-products and changing regional climate has increased consumption and rate of pesticide application. These are the most harmful substances worsening toxic effects. Nine out of the twelve most hazardous and persistent organic chemicals (Aldrin, chlordane, DDT, dieldrin, endrin, heptachlor, hexachlorobenzene, mirex, toxaphene, polychlorinated biphenyls (PCBs), dioxins, furans) on the planet earth are designated as pesticide products, which are mentioned to as the "dirty dozen chemicals" (Atuma, 1999, Karlaganis et al., 2001 and Shetty et al.,2008). The pesticides have been found in workplaces, homes, schools, in food, and the community at large in our drinking and surface 
water, the air, and soil. They are usually used in a variety of ways including lawn sprays and household bug sprays and can be found in varying amounts in various fruits viz. strawberries, blueberries, and apples (Gilden et al., 2009). The extensive use of pesticides has undoubtedly prevented the harmful effect of pests and has mostly improved the productivity of crops. It has also resulted in high groundwater pollution risks. It is important to recognize groundwater pollution in agricultural areas and to evaluate the groundwater pollution risk caused due to pesticides (Zhao and Pei, 2012).

The generalized use of pesticides i.e., herbicides, insecticides and fungicides have increased risks and resulted in direct or indirect damage for both environment (soil, air and water) and human health. The efficacy of non-target organism exposure and offsite mobility has become a matter of great concern. Short-term exposure to pesticides leads to dizziness, vomiting and nausea, headaches, difficulty in sleeping, skin rashes, muscle twitches and pain, flu-like fever, and breathing difficulties. In contrast, the long-term exposure to pesticides can cause to more severe diseases i.e., cancers, brain damage in children, lowered $I Q$, and permanent kidney damage due to its long term exposure. Exposure to a high concentration of pesticides could result in death (Chopra et al., 2011).

The undegradable pesticide residues may enter into the food chains through air, water and soil and cause several health problems to the living beings of the ecosystems, including humans. Pesticides can be carcinogenic or cytogenic and may cause bone marrow diseases, infertility, nerve disorders and immunological and respiratory diseases. The toxicological and epidemiological studies observed the potential health risks of cancer, genetic malformations, neuro-developmental disorders and damage of the immune system (Skinner et al., 1997; Sanborn et al., 2004; McKinlay et al., 2008). Globally, more than three million of acute poisoning cases by pesticide exposure and the estimated mortality of 0.3 million annually has been reported (Usha, et al., 2017). Occupational exposure to pesticides has been linked to a multiplicity of disorders in the medium and long term, including various neurological diseases and cancer, reproductive disorders and nervous system disorders, among other problems. The exposure is usually related to the application transportation and mixing of pesticides (Gangemi, et al., 2016).

Classification of pesticides: The pesticides are classified according to their toxicity as extremely dangerous, highly dangerous, moderately dangerous and slightly dangerous. Pesticides were also categorized on the basis of a number of parameters, including chemical structure, route of expo- sure, persistency and method of application such as herbicides, insecticides, fungicides, rodenticides, fumigants, and other categories. The most utilized pesticides are of organochlorines, organophosphates, carbamates, pyrethroids and inorganic pesticides among all categories. Organochlorine pesticides (OCPs) are categorized as a group of persistent organic pollutants (POPs), which most of these compounds have been prohibited from use due to their toxic effects(Ecobichon,2001; UNEP/GEF. 2002; Garcia et al., 2012). Another class of pesticides produced from natural material is called as a biopesticide. On the basis of their usage, pesticides have been classified as an insecticide used against insect pest, nematicides used against nematodes, fungicides used against fungi, weedicides used against weed pests (Odukkathil and Vasudevan, 2013).

Benefits of pesticides: Pesticides are substances or mixtures which play a significant role to control insects, fungal infestations, growth of weeds, either to handle immediate infestations or to anticipate long-lasting problems and also in increasing the agronomical yield for specific applications under conditions of good agricultural practice (GAP) and also to protect plants from pests, weeds or diseases and human from vector-borne diseases such as malaria, dengue fever, and schistosomiasis (Stone, 1988 and Kroeset al., 2002).

The consequences of the direct application pesticides in the control of pests and plant diseases, controlling human and animal diseases, and in control of organisms that harm other human activities and structures are known as primary benefits. The benefits arise from primary, and these are the less noticeable but are exhibited at the later stage, less naturally obvious or longer-term consequences. There are benefits to communities in terms of food security, children's education and improved quality of life among farmers. The national benefits are from export revenues and reductions in urban migration. The global benefits are in the form of the diversity of crop species that contribute to the world's food supplies, as well as prevention of the spread of a range of trans boundary diseases. The secondary benefits are more difficult to establish cause and effect, but nevertheless, they can be powerful justifications for pesticide use (Cooper and Dobson 2007; Aktar et al., 2009 and Maksymiv, 2015).

Use of pesticides : The global use of pesticides is about two million tons per year, of which $24 \%$ is consumed in the USA alone, $45 \%$ in Europe and $25 \%$ in the rest of the world. India's share is just $3.75 \%$ of the worldwide consumption of pesticides. The usage of pesticides in India is only 0.5 $\mathrm{kg} / \mathrm{ha}$, whereas in Korea and Japan, it is 6.6 and $12.0 \mathrm{~kg} / \mathrm{ha}$, respectively (Fig. 1). The $\mathrm{HCH}$ (only gamma-HCH is allowed), DDT and malathion are the most commonly used and cover $70 \%$ of the 
total pesticide consumption. Out of the total consumption of pesticides, $80 \%$ are in the form of insecticides, $15 \%$ are herbicides, $1.46 \%$ is a fungicide, and less than $3 \%$ are others. In comparison, the worldwide consumption of herbicides is $47.5 \%$, insecticides are $29.5 \%$, and fungicides, $17.5 \%$ and others account for $5.5 \%$ only. The consumption of herbicides in India is probably low because weed control is mainly done by hand weeding (Gupta, 2004). $\mathrm{HCH}$, an organochlorine insecticide, widely used in agriculture and public health, is considered to be the number one environmental contaminant in many parts of the world, particularly India and China (Srivastava and Shivanandappa, 2005). Subash et al. (2017) stated that the total consumption of pesticides increased in Maharashtra and Uttar Pradesh during the last decades, while it was slightly declined in Punjab and Haryana. It was also shown that there was a sudden decrease in the total consumption of the pesticides in the states of West Bengal, Gujarat and Karnataka, while in the states of Chhattisgarh and Kerala, there was a sudden increase in total pesticide consumption during the year 2015-16 (Table 1).

A global concern, the toxicological and ecological effects of chemicals such as pesticides are of their persistence, and bio-accumulative properties on environment, flora and fauna, and human beings. The pesticides are used as the one form of herbicides as the cost of manual weed control has ris- en due to increasing in agricultural yields (Guoet al., 2008; Eqani et al., 2012; FICCI, 2015). In India, the use of pesticides per hectare is much lesser as in comparison to other countries like China (13.06 $\mathrm{kg} / \mathrm{ha})$, Japan (11.85 kg/ha), Brazil (4.57 kg/ha) and other Latin American countries. As of $30^{\text {th }} \mathrm{Oc}-$ tober 2016, 275 pesticides are registered for agriculture, public health and use in households. As per reported by PAN India, the more than 115 pesticides out of the 275 are highly hazardous which have the reason to cause the severe health prob-

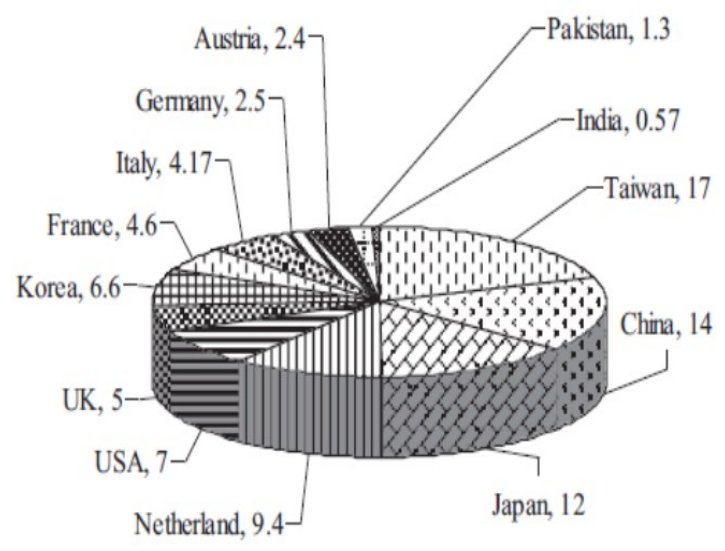

Fig. 1. Worldwide consumption $\left(\mathrm{kg} \mathrm{ha}^{-1}\right)$ of pesticides (Source: Yadav et al. 2015).

Table 1. State-wise consumption of pesticides in India (Subash et al., 2017).

\begin{tabular}{|c|c|c|c|c|}
\hline \multirow[t]{2}{*}{ States/UTs } & \multicolumn{3}{|c|}{ Total consumption (tones) } & \multirow{2}{*}{$\begin{array}{c}\text { Per ha }(\mathrm{kg}) \\
2016-17^{*}\end{array}$} \\
\hline & 2003-04 & $2008-09$ & 2015-16 & \\
\hline Punjab & 6780 & 5760 & 5743 & 0.74 \\
\hline Haryana & 4730 & 4288 & NR & 0.62 \\
\hline Maharashtra & 3385 & 2400 & 11665 & 0.57 \\
\hline Kerala & 326 & 273 & 1123 & 0.41 \\
\hline Uttar Pradesh & 6710 & 8968 & 10457 & 0.39 \\
\hline Tamil Nadu & 1434 & 2317 & 2096 & 0.33 \\
\hline West Bengal & 3900 & 4100 & 3712 & 0.27 \\
\hline Chhattisgarh & 332 & 270 & 1625 & 0.26 \\
\hline Andhra Pradesh & 2034 & 1381 & 2713 & 0.24 \\
\hline Odisha & 682 & 1156 & 723 & 0.15 \\
\hline Gujarat & 4000 & 2650 & 1980 & 0.13 \\
\hline Bihar & 860 & 915 & 831 & 0.11 \\
\hline Karnataka & 1692 & 1675 & 1434 & 0.10 \\
\hline Rajasthan & 2303 & 3333 & 2475 & 0.05 \\
\hline Madhya Pradesh & 62 & 663 & 732 & 0.03 \\
\hline All India & 41020 & 43860 & 54121 & 0.29 \\
\hline
\end{tabular}

NR refers to not reported; * Gross Cropped Area (GCA) based on 2014-15 
lems such as acute toxicity and chronic effect like cancers, endocrine disruption, hormonal, reproductive and developmental disorders (Kumar and Reddy, 2017 and FAOSTAT, 2017).

Contamination of pesticides: The pesticides, chemical formulation contaminants are dispersed into the environment to control pests. The residual pesticides contaminate the soils and water, remain in the crops and accumulate to the food chain, and finally to the humans along with food and water (Barcelo and Hennion, 1997; Taylor et al., 2003). Gurunadha Rao et al. (2004) analyzed pesticide residues, and they reported the presence of organochlorine pesticide residues of $\mathrm{BHC}$, endrin, heptachlor, heptachlor epoxide, DDT, and endosulfan in groundwater samples of Ludhiana and Muktsar districts, India. The organochlorine pesticide residues present in the groundwater of the Muktsar district were about six to eight times higher than those in the Ludhiana district, which may be attributed to cotton crop grown over a large part of Muktsar district and shallow groundwater table condition through which pesticides leach fast.

The disposal and extensive use of pesticides by farmworkers, organizations and the general public provide many possible causes of pesticide accumulation in the environment. These pesticides enter the soil and groundwater by direct treatment or being washed off from plant surfaces during rainfall. Depending on the phenotype and density of plant type, it is estimated that an average of 35 $-50 \%$ of the plant protection material is deposited on soil immediately after spraying (Jayashree and Vasudev, 2007). Reddy and Kim (2015) acknowledged that the pesticides are functional universally due to their myriad adaptability to all environmental media such as air, water, and soil. They observed that the pesticides could cause toxic effects on various natural habitats due to their increase in exceeding concentration level regularly beyond the permissible levels in the environment (Fig. 2).

\section{INFLUENCE OF PESTICIDES}

The environmental problems associated with pesticides are of great concern not only in developed countries but also in developing countries. These pesticides are highly toxic and bioaccumulative and have caused serious effect on soil, air, water, sediment, and environment, often being biomagnified through the food chain to affect the health of individual organisms at higher trophic levels (Gomes et al. 1999). The pesticides can be transported through surface runoff, leaching, and vapor phase and generally, estuarine and marine sediments are the temporary or long-term ultimate sinks for most of OCs. Consequently, these sediments act later as secondary sources of these substances reaching the ocean and biota (Arias et al., 2011).

The release of the pesticide into the environment

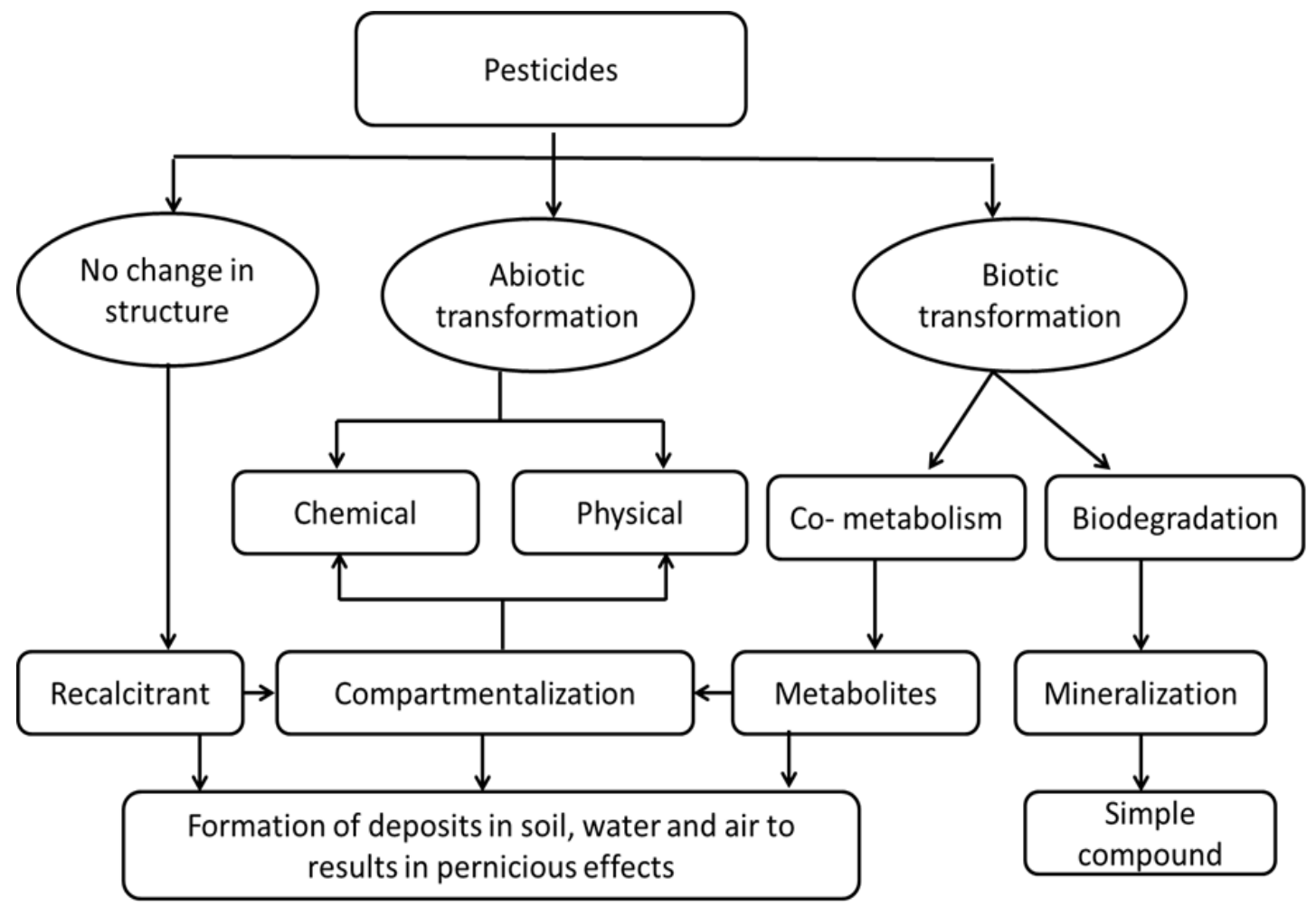

Fig. 2. Environmental fate and transport of pesticides in natural ambient conditions (Source: Reddy and Kim, 2015). 
and their quality as active substances designed to control pests and weeds efficiently lay the foundation for the risk of widespread effects of pesticides on nontarget organisms (Kattwinkelet al., 2015). The pesticide contamination in the environment and their consequences on human and ecosystem health are a major concern. At present, to understand the harmful effects of pesticides is to be needed by conducting strong research determinations to reduce the harmful effects. To reduce the risks related to the dispersion of pesticides in the environment and to decrease their harmful impacts on biodiversity, ecosystem functions, and human health is the prime concern and to notify the public of the nation about the policies and regulation of the pesticides (Pelosi et al., 2017).

Aquatic toxicity: The aquatic toxicity is an important parameter in evaluating the potential adverse environmental impact due to the widespread mortality of fish and marine invertebrates due to the contamination of aquatic systems by pesticides. The presence of toxic substances in receiving waters and water treatment plants is a major environmental concern (Indoratoet al., 1984 and Strayer 2006). Pesticide residues reach the aquatic environment through fallout, drainage, or runoff erosion, and from the discharge of industrial effluents containing pesticides, leaching, careless disposal of empty containers, equipment washing into waterways. These are particularly toxic to many non-intended freshwater species and can have lasting impacts on these ecosystems (Zacharia, 2011). Subsequently, people are likely to be exposed to pesticides in these regions. Pesticides may persist for a long period of time and increase the probability of exposure and posing potential risks to both humans and aquatic organisms (Navarrete et al., 2018).

Terrestrial toxicity: A large number of chemical formulations used in pesticides are persistent in the terrestrial environment and also affect the soil organisms involved in the process of the natural nutrient cycle in the ecosystem.Pesticides hinder the growth of higher plants in the soil during the process of nitrogen fixation. The legumerhizobium chemical signaling reduces the nitrogen fixation and thus reduces crop yields by the interface with insecticides DDT, methyl parathion and especially pentachlorophenol (Rockets, 2007).

The application schedules of pesticides are verbalized by crop pest/weed infestation levels and other management practices. The application period can have different impacts. The dimethoate insecticide applied to barley crops at maximum rates $(0.4 \mathrm{~kg} / \mathrm{ha})$ during the early (spring) was very harmful to seven non-target soil-dwelling breeding beetles while sprayed in autumn at the same rate reduces the impact on populations of old beetles (Gyldenkærne et al., 2000). The spray droplets of pesticides made of the concentrated active ingredient in an oily or water-based carrier solution sometimes contain an adjuvant. These tiny droplets of $100-200 \mathrm{~mm}$ in diameter deliver a concentrated dose of a toxicant to the skin, hair and feathers of animals (Hewitt et al., 2002). The bioavailability of pesticidal residues in soil and sediment decreases considerably with time. However, many animals continue to show DDT/DDE in their body tissues even decades after. The highest residues were DDT (35-1980 mg/L) and its metabolite DDE $(2-21 \mathrm{mg} / \mathrm{L})$ even if it had not been used in that country for 20 years ( Ahmad et al., 2004).

\section{PREVENTIVE MEASURES TO THE PESTICIDES EXPOSURE}

The application of appropriate preventive measures helps to minimize cases of pesticide poisoning and other health risks linked to pesticide use. This can be achieved with minimal use of pesticides using accurate diagnosis and advanced knowledge of pest problems, optimized timing of interventions for maximum long-term efficiency, selection of a pesticide product with minimum impact on non-target organisms and the operator, and improved application of the selected product for maximum dose transfer to the biological target (Dent, 2005). The exposure to pesticides can be reduced through less use of pesticides and various procedures, such as integrated pest management (IPM), the prohibition of highly hazardous pesticides, restricting the use of toxic compounds, alternative cropping systems and the correct use of personal protective equipment (PPE) in all stages of pesticide handling (Damalas et al., 2016)

Alternative cropping systems: The approach of Alternative cropping system is essential to reduce the exposure to pesticides that is less dependent on pesticides. The purpose of this approach is to increase the abilities of agricultural crop systems to induce the natural processes of pest regulation and to contribute to the improvement of the agricultural production (Struik, and Kropff, 2003). Alternative agricultural practices such as conservation tillage, selected crop varieties, biological regulations of bioagressors at the plot, farm, and landscape scales may significantly contribute to decrease the pesticide pressure (Pelosi et al., 2017).

Use of personal protective equipment (PPE): For reducing the pesticide exposure,the personal protective equipment (PPE) is one of most widely assumed to defend workers from the pesticidal effects. Thefabric is less capable of infiltration and provide the maximumdefense from exposure of pesticide for workers. Although the indications of effectiveness show that PPE is frequently not used for farmers and applicators (Perry et al. 
2002 and Quandtet al. 2006 ). The protection against exposure of pesticides according to fabric type, including thickness and weight. Garments of both barrier and non-barrier fabrics were found to decrease dermal exposure (Coffman et al., 2009). The design strategies of pesticides will remain a tool for modern agriculture. Dressing properly and using personal protective equipment (PPE) can help to reduce the pesticide exposure and decrease the pesticide poisoning (Ekströmand Ekbom, 2011).

Several types of personal protective equipments (PPE) like gloves, boots, hats, long sleeve shirts, and chemical-resistant coveralls are among the most common types of PPE being used and the formulations (liquid, granular and wet table powder etc.). It is very essential to take the precaution and use common sense if the pesticides do not have the specific requirement regarding the use of PPE (Ogg et al., 2018). The highly toxic pesticides require the use of multiple types of PPE for reducing exposure. Different types of PPE provide complementary levels of personal protection against dermal exposure. The Wearing gloves among US citrus farmers was found to be the most effective protection method against dermal pesticide exposure by $27 \%$ and was further was reduced by $65 \%$ when both gloves and coveralls were used (Damalas et al.,2016).

Integrated pest management (IPM): The indiscriminate use of pesticides, pest resistance, pest resurgence, the outbreak of secondary pest present additional challenges to the society. The presence of pesticide residues in food, fodder, soil, air and water ultimately leads to human health hazards and ecological imbalances.

Adopting an Integrated Pest Management (IPM) is very effective among the various methods for controlling pests. This is an eco-friendly method for managing pests without greatly affecting the health of man or the environment. IPM is the substitute practice of ecologically safe pest control practices using multifaceted approach to pest management to reduce the indiscriminate use of pesticides(Gill and Garg, 2013). The use of thresholds for decisions, and spans methods from pesticide product management/substitution to whole agroecosystem redesign to follow the management and assimilation strategies of IPM. It utilizes need based use of chemical pesticides, preferably biopesticides, bio-control agents, cultural, mechanical and biological methods and indigenous innovation potential (Yadav et al. 2015 and Pretty and Bharucha,2015).

Integrated pest management is a vital step towards providing healthy, viable food for a growing global population. Small farm houses are the important part of agricultural production that have the significant role in biological and societal welfares, including protection of agricultural biodiversity and enriched the food security. Although the small farm sector is presently insufficient. The development and implementation of Integrated Pest Management (IPM) practices could help increase such benefits at the small scale farms. (Alam et al., 2016 and Grasswitz 2019).

Protection and regulation policy in pesticide application: Though the use of pesticides is necessary to protect agricultural crops from pests and to control vector borne disease, the regulatory system has had to take into consideration its residues in food and water. An appropriate controls of pesticide application in the form of rules and legislation must be customized to well-built the risk/ benefit ratio. Jiménez et al. (1999) elucidated that the purpose of launched the standards is to attain the benefits while reducing the hazard at a specific cost. In the developed countries, the risk and benefits are not acknowledged. The very strict values may result from the demands of ecological groups, thus producing standards based on political reasons rather than on scientific or logical reasoning. As in developing countries, it is not appropriate to facsimile such standards or strategy without analyzing the perspective under which they have been chosen and also it is very important and necessary for each nation to set up the priorities according to its actual desires and to create the criteria according to its economical and technological situation of the nation.

Regulatory restrictions should be established and managed in context with risks from other contaminants and practices to achieve an overall benefit for pesticide residues if they are to be useful and to survive legal challenges. The relationship between the limit and a toxic hazard) or legislative performance or both may be develop by the regulatory authority of limits and their comparisons of regulatory limits recognized by various national authorities Hamilton et al., 2003). Regulatory decisions or to promote co-learning actions leading to the acceptation of protection measures to reduce pesticide exposure for different groups of citizens in India, a number of government agencies are involved in the regulation of pesticides. The Ministry of Agriculture regulates the manufacture, sale, transport and distribution, export, import, and use of pesticides through the 'Insecticides Act 1968'. The formulation and use of new pesticides to control pests in various crops is approved by the Registration Committee (RC), while the Union Ministry of Health and Family Welfare monitors and regulates pesticide residue levels in food (Devi et al., 2017).

\section{Conclusion}

The benefits of pesticides provide a strong and credible argument for their continued application to increase the yield of crops and elimination of diseases caused by the pests. However, the use 
of pesticides i.e. BHC, endrin, heptachlor, heptachlor epoxide, DDT, endosulfan and pyrethroidsto the environment is of great concern harming our ecosystem and thereby causing human health risks. The increase in pesticide exposure indicates the absence of proper implementation of necessary regulations of pesticide pollution control and preventive measures. There is a need to promote the organic farming and use of biopesticides, obtained from natural products such as herbs to be encouraged for pest controlto reduce the potential contamination of air, water, soil and environment by pesticides. The intelligible and strict implementation of the Government policies and regular monitoring programme would help to assess the pesticide residue and protect the health status of water, biota and human for agriculture, biodiversity, and ecosystem management and to support the sustainable development. It is critical to devise mechanisms to make the agricultural workers more and more aware of the importance of preventive measures needed to reduce pesticide exposure and for pest management. Importance of right mechanism to apply pesticides and preventive measure to be taken while doing the same should be core of the awareness campaigns through media, social media, news and mass campaigns including government sites and apps.

\section{REFERENCES}

1. Ahmad, R., Kookana, R.S., Megharaj, M. and Alston, A.M. (2004). Aging reduces the bioavailability of even a weakly sorbed pesticide (carbaryl) in soil. Environ. Toxicol. Chem., 23(9): 2084-2089. https:// doi.org/10.1897/03-569

2. Aker W.G., Hu, X., Wang, P. and Hwang, H.M. (2008). Comparing the relative toxicity of malathion and malaoxon in blue catfish Ictalurus furcatus. Environ. Toxicol., 23:548-554. https://doi.org/10.1002/ tox. 20371

3. Aktar, M.W., Sengupta D. and Chowdhury A. (2009). Impact of pesticides use in agriculture: their benefits and hazards. Interdisc Toxicol., 2(1): 1-12. doi: 10.2478/v10102-009-0001-7

4. Alam, M.Z. Haque, M.M. Islam, M.S. Hossain, E., Hasan, S.B. Hasan S.B. and Hossain, M.S. (2016). Comparative Study of Integrated Pest Management and Farmers Practices on Sustainable Environment in the Rice Ecosystem. International Journal of Zoology, 12. http://dx.doi.org/10.1155/2016/7286040

5. Arias, A. H., Pereyra, M. T. and Marcovecchio, J. E. (2011). Multi-year monitoring of estuarine sediments as ultimate sink for DDT, $\mathrm{HCH}$, and other organochlorinated pesticides in Argentina. Environ Monit. Assess. 172:17-32. https://doi.org/10.1007/s10661-010$1315-9$

6. Atuma, S.S. (1999). Method for the determination of PCB congeners and chlorinated pesticides in human blood serum. Bull. Environ. Contam. Toxicol., 62:815. https://doi.org/10.1007/s001289900834

7. Barcelo, D. and Hennion, M.C. (1997). Trace determination of pesticides and their degradation products in water. Techniques and Instrumentation in Analytical Chemistry, 19: 542.
8. Chopra, A. K., Sharma, M.K. and Chamoli, S. (2011). Bioaccumulation of organochlorine pesticides in aquatic system-an overview. Environ Monit Assess.,173:905-916. https://doi.org/10.1007/s10661 010-1433-4

9. Coffman, C.W., Stone, J., Slocum, A.C., Landers, A.J., Schwab, C.V., Olsen, L.G. and Lee, S. (2009). Use of engineering controls and personal protective equipment by certified pesticide applicators. J. Agric. Saf. Health, 15: 311-326. https://doi.org/ 10.13031/2013.28886

10.Cooper, J. and Dobson, H. (2007). The benefits of pesticides to mankind and the environment. Crop Protection 26: 1337-1348. https://doi.org/10.1016/ j.cropro.2007.03.022

11.CSE (2003). Pesticide residues in bottled water. Centre for Science and Environment (CSE) Report, New Delhi, India.

12.Damalas, C.A. and Abdollahzadeh, G. (2016). Farmers' use of personal protective equipment during handling of plant protection products: Determinants of implementation. Sci. Total Environ.,571: 730-736. https://doi.org/10.1016/j.scitotenv.2016.07.042

13.Dent, D. (2005). Overview of agrobiologicals and alternatives to synthetic pesticides. In The Pesticide Detox: Towards a More Sustainable Agriculture; Pretty, J., Ed.; Earthscan: London, UK, 2005; pp. 70 82.

14.Devi, P. I., Thomas, J. and Raju R.K. (2017). Pesticide Consumption in India: A Spatiotemporal Analysis. Agricultural Economics Research Review, 30(1): 163-172 https://doi.org/10.5958/0974-0279.2017.00 015.5

15.Ecobichon, D. (2001). Pesticide use in developing countries. Toxicology, 160: 27-33. https:// doi.org/10.1016/S0300-483X(00)00452-2

16.Eddleston, M., Karalliedde, L., Buckley, N., Fernando, R., Hutchinson, G., Isbister, G., Konradsen, F., Murray, D., Piola, J. C., Senanayake, N., Sheriff, R., Singh, S., Siwach, S. B. and Smit, L. (2002). Pesticide poisoning in the developing world-a minimum pesticides list. Lancet 360: 1163-67. https:// doi.org/10.1016/s0140-6736(02)11204-9

17.Ekström, G. and Ekbom, B. (2011). Pest control in agro-ecosystems: An ecological approach. Crit. Rev. Plant Sci., 30: 74-94. https:/l doi.org/10.1080/07352689.2011.554354

18.Eqani S.A.M.A.S., Malik R.N., Katsoyiannis A., Zhang, G., Chakraborty, P., Mohammad, A. and Jones, K.C. (2012). Distribution and risk assessment of organochlorine contaminants in surface water from River Chenab, Pakistan. J. Environ Monit., 14:164554. https://doi.org/10.1039/C2EM11012A

19.FAOSTAT (2017). Pesticides. Food and Agriculture Organization, Rome.

20.FICCI (2015). Ushering in the 2nd Green Revolution: Role of Crop Protection Chemicals. Federation of Indian Chambers of Commerce and Industry, New Delhi.

21.FrenichGarrido A., F.J. Egea González, A. Marín Juan and J.L. Martínez Vidal (2007). Hazard Identification and Human Exposure to Pesticides Thermodynamics, Solubility and Environmental chater 24, 429-444

22.Gangemi, S., Miozzi, E., Teodoro, M., Briguglio, G., Luca, A.D., Alibrando, C., Polito, I., and Libra, M.(2016). Occupational exposure to pesticides as a 
possible risk factor for the development of chronic diseases in humans. Mol Med Rep.,14(5): 44754488. Oct 10. https://doi.org/10.3892/mmr.2016.5817 23.Garcia, F.P., Ascencio, S.Y.C., Oyarzun, J.C.G., Hernandez, A.C. and Alavarado, P.V. (2012). Pesticides: classification, uses and toxicity. Measures of exposure and genotoxic risks. J. Res. Environ. Sci. Toxicol., 1, 279-293

24.Garrido, E.M., Delerue-Matos, C., Lima, J.L.F.C. and Brett, A.M. (2004). Electrochemical methods in pesticides control. Anal. Lett. 37: 1755-1791. https:// doi.org/10.1081/AL-120039425

25.Gilden, Robyn C., Huffling, Katie, and Barbara Sattler (2010). Pesticides and Health Risks. JOGNN, 39: 103-110. https://doi.org/10.1111/j.1552-6909.200 9.01092.x

26.Gill, H. K. and Garg, H. (2013) Pesticides: Environmental Impacts and Management Strategies In.Pesticides - Toxic Aspects, InTech. http:// dx.doi.org/10.5772/57399

27.Gomes, J., Lloyd, O. L. and Revitt, D. M. (1999). The influence of personal protection, environmental hygiene and exposure to pesticides on the health of immigrant farm workers in a desert country. International Archives of Occupational and Environmental Health, 72: 40-45. https://doi.org/10.1007/ s004200050332

28.Grasswitz, T. R. (2019) Integrated Pest Management (IPM) for Small-Scale Farms in Developed Economies: Challenges and Opportunities. Insects, 10: 179. https://doi.org/10.3390/insects10060179

29.Guo, L., Uiu, Y., Zhang, G.,Zheng, G.J. Lam,P.K.S. and Li, X. (2008). Levels and bioaccumulation of organochlorine pesticides (OCPs) and polybrominateddiphenyl ethers (PBDEs) in fishes from the Pearl River estuary and Daya Bay, South China. Environ Pollut., 152:604-611. https://doi.org/10.1016/ j.envpol.2007.06.067

30.Gupta,P.K. (2004). Pesticide exposure-Indian scene. Toxicology, 198: 83-90.

31.GurunadhaRao, V. V. S., Sankaran, S., Prakash, B. A., Mahesh Kumar, K., Yadaiah, P., \& Chandrasekhar, S. V. N. (2004). Persistence of pesticide residues in groundwater of Ludhiana and Muktsar districts, Punjab. Water quality-monitoring, modelling and prediction. In Proceedings of the 11th national symposium on hydrology with focal theme on water quality held at National Institute of Hydrology (pp. 291-301). Roorkee, India, 22-23 November, 2004

32.Gyldenkærne, S., Ravn, H.P. and Halling-Sørensen, B. (2000). The effect of dimethoate and cypermethrin on soil-dwelling beetles under semi-field conditions. Chemosphere,41(7): 1045-1057. https:// doi.org/10.1016/S0045-6535(99)00511-1

33. Hamilton, D. J., Ambrus, Á., Dieterle, R. M., Felsot, A. S., Harris, C. A., Holland, P. T., Katayama, A., Kurihara, N., Linders, J., Unsworth, J. and Wong,S.S. (2003). Regulatory limits for pesticide residues in water (IUPAC Technical Report). Pure Appl. Chem., 75(8): 1123-1155.

34. Hewitt, A.J., Johnson, D.R., Fish, J. D., Hermansky, C.G. and Valcore, D.L. (2002). Development of the spray drift task force database for aerial applications. Environ. Toxicol. Chem., 21(3): 648-658. https:// doi.org/10.1002/etc.5620210326

35.Indorato, A. M., Snyder, K. B. and Usinowicz, P. J. (1984). Toxicity screening using Microtoxanalyser.
Toxicity Screening Procedures Using Bacteria! Systems. D. Liu and B. J. Dutka (eds.) pp. 37-53.

36. Jayashree, R. and Vasudev, N. (2007). Organochlorine pesticide residues in ground water of Thiruvalllur district, India. Environmental Monitoring and Assessment, 128, 209-215. https://doi.org/10.1007/s10661006-9306-6

37.Jiménez, B., Ramos, J. and Quezada I. L.(1999). Analysis of water quality criteria in Mexico. Water Sci. Technol., 40 (10): 169-173. https://doi.or g/10.1016/S0273-1223(99)00683-6

38.Karlaganis, G., Marioni, R., Sieber, I. and Weber, A (2001). The elaboration of the 'Stockholm convention'on persistent organic pollutants (POPs): a negotiation process fraught with obstacles and opportunities. Environ. Sci. Pollut. Res., 8(3): 216-221. https:// doi.org/10.1007/BF02987393

39.Kattwinkel, Mira, Liess, Matthias, Arena, Maria, Bopp, Stephanie, Streissl, Franz and Rombke,Jorg (2015). Recovery of aquatic and terrestrial populations in the contextof European pesticide risk assessment. Environ. Rev., 23: 1-13. https:// doi.org/10.1139/er-2015-0013

40.Kroes, R., Muller, D., Lambe, J., M.R.H. Lowik, , J. van, J. Kleiner, Massey, R., S. Mayer, I. Urieta, P. Verger and A. Visconti (2002). Assessment of intake from the diet. Food and Chemical Toxicology, 40: 327-385. https://doi.org/10.1016/s0278-6915(01) 00113-2

41.Kumar, D. and Reddy, D. N. (2017). High pesticide use in India: Health Implications. Health Action , 7-12

42.Maksymiv, I. (2015). Pesticides: benefits and hazards. Journal of Vasyl Stefanyk Precarpathian National University, 2(1): 70-76. https:// doi.org/10.15330/jpnu.2.1.70-76

43.McKinlay, R., Plant, J.A., Bell, J.N.B. and Voulvoulis, N. (2008). Endocrine disrupting pesticides: Implications for risk assessment. Environment International, 34:168-183. j.envint.2007.07.013

44.Navarrete, I. A.,. Tee, K. A. M., Unson J. R.I S. and Hallare A. V. (2018).Organochlorine pesticide residues in surface water and groundwater along Pampanga River, Philippines. Environ. Monit. Assess. (2018) 190: 289. https://doi.org/10.1007/s10661-0186680-9

45. Odukkathil, G. and Vasudevan, N. (2013). Toxicity and bioremediation of pesticides in agricultural soil. Rev. Environ. Sci. Biotechnol., 12:421-444. https:// doi.org/10.1007/s11157-013-9320-4

46.Ogg, C.L., Bauer, E.C., Hygnstrom, J. R., Bright, F.J., Puckett, G. J. and Alberts, C. A., (2018). Protective Clothing and Equipment for Pesticide Applicators. G758 - Index: Pesticides, General Safety 1985, 2002, 2006, 2012 - Revised November 2018 retrived from http://extensionpubs.unl.edu/.

47.Pelosi, C., Barriuso, E., Bedos. C., Benoit, P., Mamy, L. and Mougin,C. (2017). Fate and impact of pesticides: new directions to explore.Environ. Sci. Pollut. Res., 24:6841-6843. https://doi.org/10.1007/ s11356-017-8383-0

48.Perry, M.J., Marbella, A., Layde, P.M., 2002. Compliance with required pesticide-specific protective equipment use. Am. J. Industr. Med. 41 (1): 70-73. https://doi.org/10. 1002/ajim.10026

49.Pimentel, D. (2005). Environmental and economic costs of the application of pesticides primarily in the 
United States. Environment, Development and Sustainability, 7: 229-252. https://doi.org/10.1007/ s10668-005-7314-2

50.Pretty, J. and Bharucha, Z. P. (2015) Integrated Pest Management for Sustainable Intensification of Agriculture in Asia and Africa. Insects, 6: 152-182. https://doi.org/10.3390/insects6010152

51.Quandt, S. A., Hernández-Valero, M. A., Grzywacz, J. G, Hovey, J. D., Gonzales, M., and Arcury,T.A. (2006). Workplace, Household, and Personal Predictors of Pesticide Exposure for Farmworkers.Environmental Health Perspective, 114(6)

52.Reddy, P. VenkataLaxma and Kim, Ki-Hyun (2015) A review of photochemical approaches for the treatment of a wide range of pesticides. Journal of Hazardous Materials, 285: 325-335. https:// doi.org/10.1016/j.jhazmat.2014.11.036

53.Rockets, R. (2007). Down On The Farm? Yields, Nutrients And Soil Quality. Scienceagogo.com. Retrieved on September 15, 2007.

54.Sanborn, M., Cole, D., Kerr K., Vakil, C., Sanin, K.H., Bassil K.(2004). Systematic review of pesticide human health effects. Canada: The Ontario College of Family Physicians.

55.Shetty, P.K., Murugan, M. and Sreeja, K.G. (2008). Crop protection stewardship in India: wanted or unwanted. Curr Sci., 95(4):457-464.

56.Skinner JA, Lewis KA, Bardon KS, Tucker $P$, Catt JA, Chambers BJ (1997). An overview of the environmental impact of agriculture in the UK. J Environ Manage., 50 (2):111-28

57.Srivastava, A. and Shivanandappa, T. (2005). Haxachlorocylohexane differentially alters the antioxidant status of the brain regions in rat. Toxicology, 214:123 -130. https://doi.org/10.1016/j.tox.2005.06.005

58.Stone, B., 1988. Developments in agricultural technology. China Quarterly, 110, 767-822.

59.Struik, P.C. and Kropff, M.J. (2003). An agricultural vision. In Pesticides: Problems, Improvements, Alternatives; den
60.Subash SP, Prem Chand, Pavithra S, Balaji SJ and Suresh Pal (2017) Pesticide Use in Indian Agriculture: Trends, Market Structure and Policy Issues. Policy Brief, 43, December 2017

61.Taylor, M., Klaine, S., Carvalho, F.P., Barcelo, D. and Everaarts, J. (2003). Pesticide Residues in Coastal Tropical Ecosystems. Distribution, Fate and Effects. Taylor and Francis, London.

62.Usha, M., Kumar BP, S., Jose, S.M., Sebastian, E. J. and Wagle, L. (2017). Developing a Standard Treatment Protocol Towards Organophosphorus Poisoning for Emergency Department in a Hospital, India. J. Basic Clin. Pharma., 8 (S1):S64-71.

63.UNEP/GEF. (2002). Regionally Based Assessment of Persistent Toxic Substances: South East Asia and South Pacific Regional Report. United Nations, Geneva. Switzerland. p 1-53.

64.Yadav, I. C., Devi, N. L., Syed, J. H., Cheng, Z., Li, J., Zhang, G. and Jones, K. C.(2015). Current status of persistent organic pesticides residues in air, water, and soil, and their possible effect on neighboring countries: A comprehensive review of India. Science of the Total Environment 511: 123-137. https:// doi.org/10.1016/j.scitotenv.2014.12.041

65.Zacharia, J. T. (2011). Ecological Effects of Pesticides, Pesticides in the Modern World - Risks and Benefits, Dr. Margarita Stoytcheva (Ed.), ISBN: 978953-307-458-0, InTech,

66.Zhao, X. and Hwang, H.M. (2009). A study of the degradation of organophosphorus pesticides in river waters and the identification of their degradation products by chromatography coupled with mass spectrometry. Arch. Environ. Contam. Toxicol., 56:646-653. https://doi.org/10.1007/s00244-0089220-8.

67.Zhao, Y.Y. and Pei, Y.S. (2012). Risk evaluation of groundwater pollution by pesticides in China: a short review. Procedia Environmental Sciences 13: 1739 1747. https://doi.org/10.1016/j.proenv.2012.01.167 